\begin{tabular}{|c|c|}
\hline Title & $\begin{array}{l}\text { Low-temperature annealing behavior of defects in Mg-ion-implanted GaN studied using MOS diodes and } \\
\text { monoenergetic positron beam }\end{array}$ \\
\hline Author(s) & A kazawa, Masamichi; Kamoshida, Ryo; Murai, Shunta; Kachi, Tetsu; Uedono, A kira \\
\hline Citation & $\begin{array}{l}\text { Japanese Journal of A pplied Physics (JJA P), 60(1), } 016502 \\
\text { https://doi.org/10.35848/1347-4065/abcf08 }\end{array}$ \\
\hline Issue Date & 2021-01-01 \\
\hline DOC URL & http:/hdl .handle.net/2115/83719 \\
\hline Rights & (O2021 The Japan Society of A pplied Physics \\
\hline Type & article (author version) \\
\hline File Information & JJAP_RP_MOSPAS_HUSCAP.pdf \\
\hline
\end{tabular}

Instructions for use 


\section{Low-temperature annealing behavior of defects in Mg-ion- implanted GaN studied using MOS diodes and monoenergetic positron beam}

Masamichi Akazawa ${ }^{1,{ }^{*}}$, Ryo Kamoshida ${ }^{1}$, Shunta Murai ${ }^{1}$, Tetsu Kachi ${ }^{2}$, and Akira Uedono ${ }^{3}$ ${ }^{1}$ Research Center for Integrated Quantum Electronics, Hokkaido University, Sapporo, Hokkaido 060-0813, Japan

${ }^{2}$ Institute of Materials and Systems for Sustainability, Nagoya University, Nagoya, Aichi 464-8601, Japan

${ }^{3}$ Division of Applied Physics, Faculty of Pure and Applied Science, University of Tsukuba, Tsukuba, Ibaraki 305-8573, Japan

E-mail: akazawa@rciqe.hokudai.ac.jp

$\mathrm{Mg}$ ions were implanted into Si-doped $\left(5 \times 10^{17} \mathrm{~cm}^{-3}\right) \mathrm{n}$-GaN at a dose of $1.5 \times 10^{11}$ or $1.5 \times 10^{12}$ $\mathrm{cm}^{-2}$. MOS diodes were used to characterize the implanted $\mathrm{GaN}$ after $300{ }^{\circ} \mathrm{C}$ annealing for $3 \mathrm{~h}$ and after additional $500{ }^{\circ} \mathrm{C}$ annealing for $3 \mathrm{~min}$. Although capacitance-voltage $(C-V)$ characteristics varied with the dosage, the effects of acceptor-like defects induced by ion implantation were observed in the $C-V$ characteristics independently of dosage and annealing temperature. A defect level at approximately $0.25 \mathrm{eV}$ below the conduction band edge was detected electrically. By positron annihilation spectroscopy, its origin was identified as a divacancy consisting of $\mathrm{Ga}$ and $\mathrm{N}$ vacancies. It was found that its density compared with that of as-implanted GaN decreased with $300{ }^{\circ} \mathrm{C}$ annealing, and further increased with $500{ }^{\circ} \mathrm{C}$ annealing. This phenomenon was explained on the basis of the difference between the diffusion barriers of possible point defects. 


\section{Introduction}

$\mathrm{GaN}$ has revolutionized optoelectronics with the introduction of high-brightness lightemitting diodes ${ }^{1,2)}$. Recently, this material has attracted attention as a promising material for power devices $^{3-5)}$ because of its wide bandgap ${ }^{5)}$, high breakdown field ${ }^{6}$, good thermal conductivity ${ }^{5)}$, high electron mobility at low electric fields ${ }^{5)}$, and high electron saturation velocity at high electric fields ${ }^{7)}$. In addition, an excellent metal-oxide-semiconductor (MOS) structure with a thoroughly minimized interface state density can be obtained by carefully depositing an insulator on a GaN surface ${ }^{8-11)}$, which leads to the realization of highefficiency power devices, such as vertical MOS field-effect transistors ${ }^{4,}{ }^{12-14)}$. In the fabrication of power devices, ion implantation is a convenient method for forming a selectively doped region as a building block. However, for GaN, ion implantation for forming a p-type region has been difficult.

Recently, p-type conductivity has been reported to be achieved by Mg ion implantation combined with high-temperature annealing to activate $\mathrm{Mg}$ acceptors and recover defects. Rapid thermal annealing (RTA) with sequential pulse heating, named multicycle RTA, has been reported to be efficient for activating $\mathrm{Mg}$ acceptors ${ }^{15-18)}$. Although this method was carried out under a nitrogen overpressure of $2 \mathrm{MPa}$, it has been reported that a p-type region can be obtained by $\mathrm{Mg}$ ion implantation combined with annealing at a temperature higher than $1230{ }^{\circ} \mathrm{C}$ even in atmospheric-pressure nitrogen ${ }^{19-22)}$. However, the activation rate seems to be higher for annealing under the nitrogen overpressure. Moreover, ultrahigh-pressure annealing in which Mg-ion-implanted GaN was annealed at $1400{ }^{\circ} \mathrm{C}$ or higher under a nitrogen overpressure of $1 \mathrm{GPa}$ was performed, resulting in a successful generation of holes confirmed by the temperature dependence of the Hall effect with a high activation ratio ${ }^{23}$.

In addition to obtaining a p-type region successfully, defect levels generated by $\mathrm{Mg}$ ion implantation have also been investigated. Deep-level transient spectroscopy (DLTS) using Schottky barrier diodes revealed several defect levels at $0.2-1.1 \mathrm{eV}$ below the conduction band edge $E_{\mathrm{C}}$ in $\mathrm{Mg}$-ion-implanted $\mathrm{GaN}$ after annealing at various temperatures up to 1000 ${ }^{\circ} \mathrm{C}^{24)}$. Another approach has been used for the electrical measurement of defect levels using a MOS structure with Mg-ion-implanted $\mathrm{GaN}^{25-27)}$. Both approaches were used for evaluating lightly $\mathrm{Mg}$-ion-implanted $\mathrm{GaN}$ that exhibited n-type conduction, which enabled the comparison of the results with a vast amount of previously reported data on defect levels detected in n-type $\mathrm{GaN}^{28-36)}$. Nevertheless, the assignment of defects by a method other than electrical measurements has not been performed to investigate the effects of low-temperature annealing on $\mathrm{Mg}$-ion-implanted GaN. 
On the other hand, positron annihilation spectroscopy (PAS) is a powerful method for analyzing vacancy defects in various materials. This method has been applied to Mg-ionimplanted $\mathrm{GaN}^{37-40)}$. On the basis of the results of PAS for room-temperature $\mathrm{Mg}$ ion implantation, the Ga-N divacancy $\left(V_{\mathrm{Ga}} V_{\mathrm{N}}\right)$ was mainly detected for as-implanted samples ${ }^{38)}$. Upon annealing at $1000{ }^{\circ} \mathrm{C}$, vacancy agglomeration occurred to form vacancy clusters. It was suggested that vacancy defects existed even after annealing at $1300{ }^{\circ} \mathrm{C}$, which can cause carrier trapping and scattering. Such defects may lower the activation rate of $\mathrm{Mg}$ and affect the device performance. To realize a power device with excellent performance, methods of controlling defects should be developed. Although high-temperature annealing cannot eliminate defects completely, a clue to developing a method of controlling defects might be obtained by investigating the behavior of defects generated by ion implantation upon lowtemperature annealing.

In this study, we investigate the behavior of defects generated by Mg ion implantation upon annealing at 300 and $500{ }^{\circ} \mathrm{C}$ by a combination of electric measurement using MOS diodes and analysis using a monoenergetic positron beam. In addition to the Ga vacancy $\left(V_{\mathrm{Ga}}\right)$ and its clusters with the $\mathrm{N}$ vacancy $\left(V_{\mathrm{N}}\right)$, we also discuss the behavior of interstitial $\mathrm{Ga}$ $\left(\mathrm{Ga}_{i}\right)$ and interstitial $\mathrm{N}\left(\mathrm{N}_{i}\right)$.

\section{Experimental procedure}

Samples were prepared as shown in Fig. 1 and as described below. A Si-doped n-GaN layer ( $3 \mu \mathrm{m}$ thick, $n=5 \times 10^{17} \mathrm{~cm}^{-3}$ ) was grown on a free-standing $\mathrm{n}^{+}-\mathrm{GaN}(0001)$ substrate via an $\mathrm{n}^{+}$-GaN buffer layer by metalorganic vapor phase epitaxy (MOVPE). Mg ions were implanted at room temperature at an energy of $50 \mathrm{keV}$, an angle of $7^{\circ}$, and a dose of $1.5 \times 10^{11}$ or $1.5 \times 10^{12} \mathrm{~cm}^{-2}$. The depth profiles of the $\mathrm{Mg}$ concentration, $[\mathrm{Mg}]$, were measured by secondary ion mass spectroscopy (SIMS). Figure 2 shows the SIMS [Mg] profile for the asimplanted low-Mg-ion-dose sample in comparison with the calculation results obtained using the "stopping and range of ions in matter (SRIM)" code for $[\mathrm{Mg}]$, the concentration of $V_{\mathrm{Ga}},\left[V_{\mathrm{Ga}}\right]$, and that of $V_{\mathrm{N}},\left[V_{\mathrm{N}}\right]$. The calculated $[\mathrm{Mg}]$ is in good agreement with the SIMS result at the top of the profile, although the tail in the SIMS profile indicated a trace of the channeling phenomenon. Note that high $\left[V_{\mathrm{Ga}}\right]$ and $\left[V_{\mathrm{N}}\right]$ are calculated. Since the vacancies are accompanied by interstitials, the concentrations of $\mathrm{Ga}_{i}$ and $\mathrm{N}_{i}$ can be in a similar order to $\left[V_{\mathrm{Ga}}\right]$ and $\left[V_{\mathrm{N}}\right]$. Therefore, we can expect the detection of the defects produced by implantation. Thereafter, for the samples with $500{ }^{\circ} \mathrm{C}$ annealing, a 20 -nm-thick $\mathrm{Al}_{2} \mathrm{O}_{3}$ layer was formed by atomic layer deposition (ALD) using trimethylaluminum and $\mathrm{H}_{2} \mathrm{O}$ at a 
substrate temperature of $300{ }^{\circ} \mathrm{C}$, followed by annealing at $500{ }^{\circ} \mathrm{C}$ for 3 min under nitrogen flow and the removal of the $\mathrm{Al}_{2} \mathrm{O}_{3}$ layer. For the sample without $500{ }^{\circ} \mathrm{C}$ annealing, this process step was not carried out. The fabrication of MOS diodes was completed by forming a 30-nm-thick $\mathrm{Al}_{2} \mathrm{O}_{3}$ layer by $\mathrm{ALD}$, followed by the metallization of a $\mathrm{Ni} / \mathrm{Au}$ electrode on the top and an ohmic contact of $\mathrm{Ti} / \mathrm{Au}$ on the back surface of the GaN substrate. Finally, postmetallization annealing (PMA) was carried out for $3 \mathrm{~h}$ at $300{ }^{\circ} \mathrm{C}$ in air to reduce the interface state density $\left(D_{\mathrm{it}}\right)^{8,9)}$. For the completed MOS diodes, capacitance-voltage $(C-V)$ and capacitance-frequency $(C-f)$ measurements were carried out. The bare GaN samples for PAS analysis were prepared by removing the $\mathrm{Al}_{2} \mathrm{O}_{3}$ layer after the same annealing steps as those for the MOS diodes to ensure the same thermal history.

Although details on PAS were described previously ${ }^{37-40)}$, a brief explanation of PAS is as follows. Upon the annihilation of a positron, a $\gamma$-ray is radiated with an energy of $511 \mathrm{keV}$. When the annihilation is induced by a vacancy defect, the line width of the radiated $\gamma$-ray compared with that in the defect-free (DF) case undergoes Doppler broadening. The lineshape parameter $S$ is defined as the ratio of the integrated intensity in the range of $510.22-$ $511.78 \mathrm{keV}$ to the total integrated intensity, whereas the wing parameter $W$ is the fraction of the integrated intensity in the ranges of 504.14-507.96 and 514.04-517.86 keV. By measuring $S$ at various positron energies, we obtained the depth profile of $S$ increased by the vacancy defects. The relationship between $S$ and positron energy was analyzed using VEPFIT, a computer program developed by van Veen et al. ${ }^{41)}$ Moreover, by coincidence Doppler broadening (CDB) measurement, where $S$ and $W$ are measured coincidentally, we can assign a defect by comparison with the theoretically calculated $S-W$ relations for possible vacancy defects. The Doppler broadening spectra of positrons corresponding to the annihilation of positrons were calculated using the quantum materials simulator (QMAS) code. This program adopts the projector augmented-wave (PAW) method ${ }^{42)}$ to obtain electron wave functions. Details of the calculation procedure are described elsewhere. ${ }^{43}$ )

\section{Results and discussion}

\subsection{Electrical properties of MOS diodes}

In the case of the lower $\mathrm{Mg}$ ion dose, the MOS diodes with $300{ }^{\circ} \mathrm{C}$ annealing exhibited anomalous $C-V$ characteristics as shown in Fig. 3(a), where the bias voltage was swept from the negative side to the positive side. Here, the ideal curve assuming no implantation was calculated with the same flat-band-voltage shift as the experimental $C-V$ curve of the MOS diode with unimplanted $\mathrm{n}-\mathrm{GaN}$. Around zero bias, the slope of the $C-V$ curve is steeper than 
that of the ideal curve. In addition, a plateau can be seen distinctly. These results indicate that defects existed in the bulk of the Mg-ion-implanted GaN. In particular, the anomalously steep region appearing on the right side of the ideal curve indicates that an acceptor-like defect compensating for the Si donor existed predominantly in $\mathrm{GaN}^{44,45)}$. Furthermore, a slight frequency dispersion was observed. Although the frequency dispersion and the plateau of the $C-V$ characteristics were reduced by $500{ }^{\circ} \mathrm{C}$ annealing as shown in Fig. 3(b), the anomalously steep region still existed, indicating that the acceptor-like bulk defect persisted.

Since the measured $C-V$ curves are affected by the acceptor-like defect being partially steeper than the ideal curve, the high-frequency capacitance method for deriving the interface state density $D_{\text {it }}$ cannot be applied to the $1 \mathrm{MHz} C-V$ curves in Figs. 3(a) and 3(b). Instead, we applied the high-low-frequency capacitance method to $1 \mathrm{MHz}$ and $1 \mathrm{kHz} C-V$ curves. In this method, $D_{\mathrm{it}}$ is derived from the high-frequency-limit capacitance $C_{\mathrm{HF}}$ and the low-frequency-limit capacitance $C_{\mathrm{LF}}$ according to ${ }^{46)}$

$D_{i t}=\frac{1}{q^{2}}\left(\left(\frac{1}{C_{L F}}-\frac{1}{C_{O X}}\right)^{-1}-\left(\frac{1}{C_{H F}}-\frac{1}{C_{O X}}\right)^{-1}\right)$,

where $C_{\mathrm{OX}}$ is the oxide capacitance. Here, the position of the surface Fermi level $E_{\mathrm{FS}}$ corresponding to $V$ was calculated by ${ }^{46)}$

$E_{C}-E_{F S}=\int_{V_{0}}^{V}\left(1-\frac{C_{L F}}{C_{O X}}\right) d V$

where $V_{0}$ is the voltage for strong accumulation. Regarding the $1 \mathrm{kHz}$ and $1 \mathrm{MHz}$ capacitances as $C_{\mathrm{LF}}$ and $C_{\mathrm{HF}}$, respectively, we derived the $D_{\mathrm{it}}$ distribution in the range near $E_{\mathrm{C}}$ where the time constants of the interface states are sufficiently small. The result is shown in Fig. 4. Here, the detected traps are assigned to not only the interface states but also the bulk traps as discussed later. Therefore, the derived density distribution should be labeled as the trap density $D_{\mathrm{T}}$ distribution. A discrete level seems to exist at around $E_{\mathrm{C}}-0.25 \mathrm{eV}$ for the sample annealed at $300{ }^{\circ} \mathrm{C}$. For the sample annealed at $500{ }^{\circ} \mathrm{C}$, this level may be merged with the near- $E_{\mathrm{C}}$ edge of the continuous interface state density distribution having a $U$ shape over the entire band gap. It can be seen that the $D_{\text {T }}$ distribution at the energy position deeper than $E_{\mathrm{C}}-0.3 \mathrm{eV}$ disappeared after $500{ }^{\circ} \mathrm{C}$ annealing, which might have led to the reduction in the frequency dispersion and that in the plateau length of $C-V$ curves.

With an increase in $\mathrm{Mg}$ ion dose, the $C-V$ characteristics changed markedly. As shown 
in Fig. 5(a), a marked frequency dispersion was observed. In addition, a long plateau was also observed in the negative bias region. Although the length of the plateau was decreased by $500{ }^{\circ} \mathrm{C}$ annealing during MOS diode fabrication as shown in Fig. 5(b), the severity of frequency dispersion was not diminished markedly. To investigate the frequency dispersion in detail, $C-f$ measurement was carried out. The obtained characteristics are shown in Figs. 6(a) and 6(b) for the $300-{ }^{\circ} \mathrm{C}$-annealed and $500-{ }^{\circ} \mathrm{C}$-annealed samples, respectively, which showed very similar characteristics. This type of frequency dispersion was caused by strong Fermi level pinning.

There is a possibility that the observed Fermi level pinning was caused by the $\mathrm{Al}_{2} \mathrm{O}_{3} / \mathrm{GaN}$ interface states. To examine this possibility, the $C-f$ characteristics were analyzed. The interface state conductance $G_{\mathrm{p}} / \omega$ can be obtained as ${ }^{46}$ )

$\frac{G_{p}}{\omega}=\frac{C_{O X}^{2}\left(G_{m} / \omega\right)}{\left(G_{m} / \omega\right)^{2}+\left(C_{O X}-C_{m}\right)^{2}}$,

where $\omega$ is the angular frequency, $C_{\mathrm{m}}$ is the measured capacitance, and $G_{\mathrm{m}}$ is the measured conductance. The analysis results are shown in Figs. 7(a) and 7(b) for the $300{ }^{\circ} \mathrm{C}$-annealed and $500-^{\circ} \mathrm{C}$-annealed samples, respectively, which show that the frequency range where the conductance peak was detected was not affected by the annealing temperature. In these figures, the solid circles show experimental data, whereas the solid lines are fitted lines, assuming a single time constant $\tau$, according to ${ }^{46)}$

$\frac{G_{p}}{\omega}=\frac{\omega \tau}{1+\omega^{2} \tau^{2}} C_{i t}$

where $C_{\text {it }}$ is the interface state capacitance. The experimental data are well fitted by the single-time-constant model, which indicates that the interface states have single time constants. This seems to be unusual because, in a typical case, the time constants of the interface states cannot be determined singly and they distribute in a certain range. $D_{\text {it }}$ was derived as ${ }^{46)}$

$D_{i t}=\frac{C_{i t}}{q^{2}}$

where $q$ is the elementary charge. To obtain the $D_{\mathrm{T}}$ distribution in the band gap, the bias 
voltage $V$ that varies the surface potential $\psi \mathrm{s}$ was changed as indicated in Figs. 6 and 7. $\psi \mathrm{s}$ corresponding to each $V$ can be derived from the high-frequency-limit $C-V$ curve, which leads to the determination of the energy position of the detected interface states. However, the high-frequency-limit $C-V$ curve was not achieved in the present data. On the other hand, the energy $E_{\mathrm{T}}$ of an electron trap is related to the electron emission time constant corresponding to $\tau$ as $^{24,28,35)}$

$\tau=\frac{1}{\sigma v_{t h} N_{C}} \exp \left(\frac{E_{C}-E_{T}}{k T}\right)$

where $\sigma$ is the capture cross section of the interface state, $v_{\text {th }}$ is the thermal velocity of electrons, $N_{\mathrm{C}}$ is the density of states at $E_{\mathrm{C}}, k$ is the Boltzmann constant, and $T$ is the temperature. Here, $E_{\mathrm{C}}-E_{\mathrm{T}}$ was determined by solving Eq. (6) assuming $\sigma$ to be $1 \times 10^{-16} \mathrm{~cm}^{-}$ ${ }^{2}$ with reference to the previous results of the DLTS study of defect levels in $\mathrm{GaN}^{32)}$.

The $D_{\mathrm{T}}$ distributions derived from $G_{\mathrm{p}} / \omega$ peaks are shown in Fig. 8 for the two annealing temperatures considered. A very similar discrete level at around $E_{\mathrm{C}}-E_{\mathrm{T}}=0.25 \mathrm{eV}$ was derived clearly for both annealing temperatures, which also means that the surface Fermi level was pinned at around $E_{\mathrm{C}}-0.25 \mathrm{eV}$ by this level despite the large bias change. According to the disorder-induced-gap-state model that is a guiding principle concerning the origin of interface states, the $D_{\text {T }}$ distribution should have a $U$ shape in the entire band gap ${ }^{47}$, 48). However, a discrete level can be detected when high-density bulk defects exist in the vicinity of the semiconductor surface ${ }^{49,50)}$. Therefore, the detected discrete level should have been the bulk defect level. The same discussion can be applied to the $D_{\mathrm{T}}$ distribution derived for the low-Mg-ion-dose sample as shown in Fig. 3. A similar defect level was previously reported to be observed at around $E_{\mathrm{C}}-E=0.25 \mathrm{eV}^{28-30,32-34,36)}$. According to the literature, this defect level can be assigned to the divacancy $\left.V_{\mathrm{Ga}} V_{\mathrm{N}} 29,30,32,34\right)$ that is an acceptor-like defect. Moreover, without the compensation for the $\mathrm{Si}$ donor in the GaN bulk, the capacitance at the deep depletion plateau of the $C-V$ curves cannot be achieved by band bending with the surface Fermi level pinning at around $E_{\mathrm{C}}-0.25 \mathrm{eV}$. Therefore, the donor compensation by an acceptor defect should have been present inside the $\mathrm{n}-\mathrm{GaN}$ layer or the acceptor defect should have distributed in the GaN bulk.

\subsection{Analysis using monoenergetic positron beam}

As described above, the $C-V$ characteristics were highly likely affected by an acceptor-like defect independent of the dose and annealing conditions. Moreover, a possibility of the 
generation of $V_{\mathrm{Ga}} V_{\mathrm{N}}$ was indicated. However, the assignment of defect by electrical measurement is indirect. To examine the acceptor-like vacancy defect directly, PAS was performed. The positron energy dependence of $S$ is plotted for the low-Mg-ion-dose sample in Fig. 9(a) and the high-Mg-ion-dose sample in Fig. 9(b) with the variation in annealing temperature. In these figures, the mean implantation depth of positrons is also indicated at the top. DF GaN exhibits an $S$ of $0.441^{37)}$. The observed larger $S$ values indicate the existence of vacancy defects in Mg-ion-implanted GaN. $S$ increases monotonically toward the surface and with the dose. In Figs. 9(a) and 9(b), the solid lines are fitted curves with the $S$ parameter profiles as indicated in Figs. 10(a) and 10(b), respectively. In Figs. 10(a) and 10(b), the depth profiles of $[\mathrm{Mg}]$ measured by SIMS are also shown. For fitting, the region probed by positrons was divided into three blocks. The first and second blocks are damaged regions, and the third block is the DF region. It can be seen that $S$ is high in the region within $70 \mathrm{~nm}$ from the surface and is low in the deeper region of GaN. Note that the high $S$ was observed in the near-surface region where the $C-V$ characteristics of the MOS diodes are mainly affected. Independently of the dose, $S$ decreases after $300{ }^{\circ} \mathrm{C}$ annealing and increases after additional $500{ }^{\circ} \mathrm{C}$ annealing, although it is highest in the as-implanted sample.

For the defect assignment, CDB measurement was performed. The obtained $S-W$ plot for the low-Mg-ion-dose sample is shown in Fig. 11(a) and that for the high-Mg-ion-dose sample is shown in Fig. 11(b). In both figures, the brown DF data point was obtained for the unimplanted $\mathrm{GaN}^{39)}$. In Figs. 11(a) and 11(b), the data for the as-implanted GaN and 300and $500-{ }^{\circ} \mathrm{C}$-annealed samples are all along the broken line connecting the $\mathrm{DF}$ and $V_{\mathrm{Ga}} V_{\mathrm{N}}$ points. Therefore, $V_{\mathrm{Ga}} V_{\mathrm{N}}$ was detected mainly, without causing agglomeration in the temperature range considered for both $\mathrm{Mg}$ ion doses. The assignment of the $E_{\mathrm{C}}-0.25 \mathrm{eV}$ defect level detected by electrical measurement to $V_{\mathrm{Ga}} V_{\mathrm{N}}$ seems to be reasonable considering these results. It can be seen that the $(S, W)$ point after $300{ }^{\circ} \mathrm{C}$ annealing locates closer to the $\mathrm{DF}(S, W)$ point than that for the as-implanted GaN. After $500{ }^{\circ} \mathrm{C}$ annealing, however, the $(S, W)$ point shifts slightly away from the DF $(S, W)$ point. In Fig. 11(b) for the high-Mgion-dose sample, each $(S, W)$ point shifted toward the lower right compared with that in Fig. 11(a) for the low-Mg-ion-dose sample. This difference should have resulted mainly from the increase in defect density with the dose. Note that for both $\mathrm{Mg}$ ion doses, the $(S, W)$ point locates closer to the DF data point upon $300{ }^{\circ} \mathrm{C}$ annealing, indicating a decrease in the density of $V_{\mathrm{Ga}} V_{\mathrm{N}}$.

\subsection{Possible diffusion of defects}


The $S$ parameter increased and decreased upon $300{ }^{\circ} \mathrm{C}$ and $500{ }^{\circ} \mathrm{C}$ annealing, respectively, independent of the $\mathrm{Mg}$ ion dose. In the following, we outline the mechanism of the observed phenomenon by considering the diffusion of simple defects.

The diffusion coefficient $D$ is expressed as

$D=D_{0} \exp \left(-\frac{E_{A}}{k T}\right)$

where $D_{0}$ is the frequency factor and $E_{\mathrm{A}}$ is the activation energy. Generally, $E_{\mathrm{A}}$ is given by the sum of the migration barrier $E_{\mathrm{M}}$ and formation energy of defects. However, $E_{\mathrm{A}}$ is equal to $E_{\mathrm{M}}$ when a nonequilibrium density of defects exists in $\mathrm{GaN}^{51)}$, which applies to the present case for the implanted samples. According to previous reports ${ }^{51-56)}$, there is a tendency in the magnitude order of $E_{\mathrm{M}}$ of simple defects, including interstitial $\mathrm{Mg}\left(\mathrm{Mg}_{i}\right)$, in n-GaN to be $V_{\mathrm{N}}$ $>\mathrm{Mg}_{i}>V_{\mathrm{Ga}}>\mathrm{N}_{i}>\mathrm{Ga} i$. On the other hand, in $\mathrm{n}-\mathrm{GaN}$, the ionized states of these defects are considered to be $V_{\mathrm{N}}^{+}, \mathrm{Mg}_{i}{ }^{2+}, V_{\mathrm{Ga}}{ }^{2-}$ or $V_{\mathrm{Ga}}{ }^{3-}, \mathrm{N}_{i}{ }^{-}$, and $\mathrm{Ga}_{i}{ }^{2+}$ or $\mathrm{Ga}_{i}{ }^{+}{ }^{56,57)}$. Since $V_{\mathrm{Ga}} V_{\mathrm{N}}$ has a negative charge, $\mathrm{Ga}_{i}$ likely combines with $V_{\mathrm{Ga}} V_{\mathrm{N}}$ to reduce its density, whereas $\mathrm{N}_{i}$ seems to seldom combine because of the Coulomb repulsion. Since $D_{0}$ has not been measured for each defect, a quantitative discussion is difficult. In the following, we will make a qualitative discussion.

A change in defect concentration caused by diffusion can be discussed on the basis of the magnitude relation among $E_{\mathrm{M}}$ of simple defects. In the present temperature range, it is difficult for $V_{\mathrm{N}}$ to be mobile ${ }^{52)}$, and $V_{\mathrm{Ga}} V_{\mathrm{N}}$ is also considered to be immobile on the basis of a previous PAS study ${ }^{38)}$. Since $\mathrm{Ga}_{i}$ becomes mobile even at $300{ }^{\circ} \mathrm{C}^{55)}$, some $V_{\mathrm{Ga}} V_{\mathrm{N}}$ defects should have been transformed into $V_{\mathrm{N}}$ by Ga $\mathrm{Gapon}_{i} 30{ }^{\circ} \mathrm{C}$ annealing independent of the dose. It is likely that this phenomenon was observed by PAS as a decrease in $S$ after $300{ }^{\circ} \mathrm{C}$ annealing, compared with that for the as-implanted GaN shown in Figs. 9 and 10. Moreover, there is a possibility that $V_{\mathrm{Ga}}$ cannot be mobile upon $300{ }^{\circ} \mathrm{C}$ annealing but can be mobile upon $500^{\circ} \mathrm{C}$ annealing, which likely resulted in a situation where $V_{\mathrm{Ga}}$ and $V_{\mathrm{N}}$ did not combine upon $300{ }^{\circ} \mathrm{C}$ annealing but combined to form $V_{\mathrm{Ga}} V_{\mathrm{N}}$ upon $500{ }^{\circ} \mathrm{C}$ annealing. This can be the reason why $S$ increased upon $500{ }^{\circ} \mathrm{C}$ annealing. ( $E_{\mathrm{M}}$ of $\mathrm{Mg}_{i}$ is higher than that of $V_{\mathrm{Ga}}$. In addition, $[\mathrm{Mg}]$ should have been well below the concentrations of other defects on the basis of the SRIM results, as shown in Fig. 2, and the discussion in the next subsection. Therefore, we believe that the diffusion of $\mathrm{Mg}_{i}$ can be ignored.)

\subsection{Electrical properties revisited}


The dose-dependent differences in $C-V$ characteristics should have resulted from the difference in Fermi level pinning. The frequency dispersion observed for the sample with the dose of $1.5 \times 10^{12} \mathrm{~cm}^{-2}$ was caused by strong Fermi level pinning. Usually, this degree of pinning is caused by $D$ T larger than $5 \times 10^{13} \mathrm{~cm}^{-2} \mathrm{eV}^{-1}$. The reason for this is shown in Figs. 12(a) and $12(\mathrm{~b})$, where $\mathrm{d} \psi \mathrm{s} / V$ and $C_{\mathrm{LF}}$ are calculated as functions of $D_{\mathrm{T}}$, respectively, according to ${ }^{46)}$

$\frac{d \psi_{S}}{d V}=\left(\frac{C_{D}+q^{2} D_{T}}{C_{O X}}+1\right)^{-1}$

and

$C_{L F}=\left(\frac{1}{C_{O X}}+\frac{1}{C_{D}+q^{2} D_{T}}\right)^{-1}$

where $C_{\mathrm{D}}$ is the depletion capacitance and $C$ ox was assumed to be $2.5 \times 10^{-7} \mathrm{~F} / \mathrm{cm}^{2}$. When $D_{\mathrm{T}}$ is larger than $5 \times 10^{13} \mathrm{~cm}^{-2} \mathrm{eV}^{-1}, \mathrm{~d} \psi \mathrm{s} / \mathrm{d} V$ becomes smaller than $30 \mathrm{meV}$ independent of $C_{\mathrm{D}}$, and $C_{\mathrm{LF}}$ becomes large close to $C_{\mathrm{OX}}$ also independent of $C_{\mathrm{D}}$, as shown in Figs. 12(a) and 12(b), respectively. In Figs. 5(a) and 5(b), the measured $C$ becomes closer to $C$ ox on the low frequency side. Actually, $D_{\mathrm{T}}$ larger than this value was observed for the high-Mg-ion-dose sample as shown in Fig. 6. As has been shown in Fig. 3, the reduction in Mg ion dose led to a reduction in $D$ T by more than one order, which resulted in the absence of strong Fermi level pinning.

For both $\mathrm{Mg}$-ion-dose samples, the defect level at around $E_{\mathrm{C}}-0.25 \mathrm{eV}$ was detected. The $D_{\text {T }}$ of this defect was higher for the high-Mg-ion-dose sample than for the low-Mg-iondose sample. Moreover, the high-Mg-ion-dose sample exhibited higher $S$ parameters than the low-Mg-ion-dose sample, which indicated that the concentration of $V_{\mathrm{Ga}} V_{\mathrm{N}},\left[V_{\mathrm{Ga}} V_{\mathrm{N}}\right]$, was higher for the high-Mg-ion-dose sample. Therefore, it is reasonable to assign the defect level observed at around $E_{\mathrm{C}}-0.25 \mathrm{eV}$ to $V_{\mathrm{Ga}} V_{\mathrm{N}}$ as in many DLTS studies ${ }^{29,30,32,34)}$.

The difference in the magnitude of $D_{\mathrm{T}}$ of $V_{\mathrm{Ga}} V_{\mathrm{N}}$ between the low- and high-Mg-iondose samples in Figs. 4 and 8 was two orders despite the one-order difference in $\mathrm{Mg}$ ion dose. The reason for this can be explained as follows. On the basis of $C-V$ characteristics, the depletion widths with $E_{\mathrm{FS}}$ at $E_{\mathrm{C}}-0.25 \mathrm{eV}$ were $\sim 10$ and $\sim 100 \mathrm{~nm}$ for the low- and highMg-ion-dose samples, respectively. Since $D_{\mathrm{T}}$ for the bulk defect levels can be roughly given by the product of the depletion width and the defect concentration, the average $\left[V_{\mathrm{Ga}} V_{\mathrm{N}}\right]$ can 
be estimated to be on the orders of $10^{17}$ and $10^{18} \mathrm{~cm}^{-3}$ for the low- and high-Mg-ion-dose samples, respectively.

\section{Conclusions}

By the combined use of the electrical measurement using MOS diodes and PAS, we investigated the low-temperature annealing behavior of defects in $\mathrm{Mg}$-ion-implanted $\mathrm{GaN}$. $\mathrm{Mg}$ ions were implanted into Si-doped $\left(5 \times 10^{17} \mathrm{~cm}^{-3}\right) \mathrm{n}-\mathrm{GaN}$ at a dose of $1.5 \times 10^{11}$ or $1.5 \times 10^{12}$ $\mathrm{cm}^{-2}$. The fabrication of MOS diodes included $300{ }^{\circ} \mathrm{C}$ annealing. An additional $500{ }^{\circ} \mathrm{C}$ annealing was examined. PAS was performed for the samples with the same annealing conditions and also for the as-implanted sample. Although the $C-V$ characteristics changed depending on the $\mathrm{Mg}$ ion dose, the effects of an acceptor-like defect were indicated independent of the dose and annealing conditions. For the low-Mg-ion-dose sample, the $D_{\mathrm{T}}$ distribution derived by the high-low-capacitance method contained a discrete level around $E_{\mathrm{C}}-0.25 \mathrm{eV}$. By applying the conductance method to the analysis of the $C-f$ characteristics of the high-Mg-ion-dose sample that exhibited strong Fermi level pinning, the defect level around $E_{\mathrm{C}}-0.25 \mathrm{eV}$ was detected more distinctly. Moreover, $V_{\mathrm{Ga}} V_{\mathrm{N}}$ was mainly detected by PAS independent of the annealing conditions and $\mathrm{Mg}$ ion dose. Therefore, the assignment of the detected defect level around $E_{\mathrm{C}}-0.25 \mathrm{eV}$ to $V_{\mathrm{Ga}} V_{\mathrm{N}}$ is reasonable. The density of $V_{\mathrm{Ga}} V_{\mathrm{N}}$ was decreased by $300{ }^{\circ} \mathrm{C}$ annealing compared with that of the as-implanted GaN, whereas it was increased by an additional $500{ }^{\circ} \mathrm{C}$ annealing. We consider that the diffusion of $\mathrm{Ga}_{i}$ upon $300{ }^{\circ} \mathrm{C}$ annealing and that of $V_{\mathrm{Ga}}$ upon $500{ }^{\circ} \mathrm{C}$ annealing might have decreased and increased the density of $V_{\mathrm{Ga}} V_{\mathrm{N}}$, respectively.

\section{Acknowledgments}

The authors thank Dr. T. Narita of Toyota Central R\&D Labs., Inc. for the MOVPE growth of GaN epitaxial layers and for fruitful discussions. This work was supported by MEXT "Research and development of next-generation semiconductor to realize energy-saving society” Program Grant Number JPJ005357. 


\section{References}

1) H. Amano, M. Kito, K. Hiramatsu and I. Akasaki, Jpn. J. Appl. Phys. 28, L2112 (1989).

2) S. Nakamura, T. Mukai and M. Senoh, Appl. Phys. Lett. 64, 1687 (1994).

3) T. Kachi, Jpn. J. Appl. Phys. 53, 100210 (2014).

4) H. Amano et al., J. Phys. D, Appl. Phys. 51, 163001 (2018).

5) D. Ueda, in Power GaN Devices, eds. M. Meneghini, G. Meneghesso, and E. Zanoni, (Springer, New York, 2017), Ch. 1.

6) B. J. Baliga, Semicond. Sci. Technol. 28, 074011 (2013).

7) F. Schwierz, Solid-State Electronics 49, 889 (2005).

8) S. Kaneki, J. Ohira, S. Toiya, Z. Yatabe, J. T. Asubar, T. Hashizume, Appl. Phys. Lett. 109, 162104 (2016).

9) T. Hashizume, S. Kaneki, T. Oyobiki, Y. Ando, S. Sasaki, and K. Nishiguchi, Appl. Phys. Express 11, 124102 (2018).

10) T. Yamada, D. Terashima, M. Nozaki, H. Yamada, T. Takahashi, M. Shimizu, A. Yoshigoe, T. Hosoi. T. Shimura, H. Watanabe, Jpn. J. Appl. Phys. 58, SCCD06 (2019).

11) T. Nabatame, E. Maeda, M. Inoue, K. Yuge, M. Hirose, K. Shiozaki, N. Ikeda, T. Ohishi, and A. Ohi, Applied Physics Express 12, 011009 (2019).

12) T. Oka, T. Ina, Y. Ueno, J. Nishi, Appl. Phys. Express 8, 054101 (2015).

13) D. Ji, A. Agwal, H. Li, W. Li, S. Keller, S. Chowdhury, IEEE Electron Dev. Lett. 39, 863 (2018).

14) D. Ji, W. Li, A. Agwal, S. H. Chan, J. Haller, D. Bisi, M. Labrecque, C. Gupta, B. Cruse, R. Lal, S. Keller, U. K. Mishra, S. Chowdhury, IEEE Electron Dev. Lett. 39, 1030 (2018).

15) B. N. Feigelson, T. J. Anderson, M. Abraham, J. A. Freitas, J. K. Hite, C. R. Eddy, F. J. Kub, J. Cryst. Growth 350, 21 (2012).

16) T. J. Anderson, B. N. Feigelson, F. J. Kub, M. J. Tadjer, K. D. Hobart, M. A. Mastro, J. K. Hite, C. R. Eddy, Electron. Lett. 50, 197 (2014).

17) J. D. Greenlee, T. J. Anderson, B. N. Feigelson, K. D. Hobart, F. J. Kub, Phys. Status Solidi A 212, 2772 (2015).

18) T. J. Anderson, J. D. Greenlee, B. N. Feigelson, J. K. Hite, K. D. Hobart, F. J. Kub, IEEE Trans. Semicond. Manuf. 29, 343 (2016).

19) K. Nomoto, K. Takahashi, T. Oikawa, H. Ogawa, T. Nishimura, T. Mishima, H. G. Xing, T. Nakamura, ECS Trans. 69, 105 (2015).

20) T. Oikawa, Y. Saijo, S. Kato, T. Mishima, T. Nakamura, Nuclear Instruments and Methods in Physics Research B 365, 168 (2015). 
21) T. Narita, T. Kachi, K. Kataoka, T. Uesugi, Appl. Phys. Exp. 10, 016501 (2017).

22) T. Niwa, T. Fujii, T. Oka, Appl. Phys. Express 10, 091002 (2017).

23) H. Sakurai, M. Omori, S. Yamada, Y. Furukawa, H. Suzuki, T. Narita, K. Kataoka, M. Horita, M. Bockowski, J. Suda, and T. Kachi, Appl. Phys. Lett. 115, 142104 (2019).

24) G. Alfieri, V.K. Sundaramoorthy and R. Micheletto, J. Appl. Phys. 123, 205303 (2018).

25) M. Akazawa, N. Yokota and K. Uetake, AIP Advances 8, 025310 (2018).

26) M. Akazawa and K. Uetake, Jpn. J. Appl. Phys. 58, SCCB10 (2019).

27) M. Akazawa, R. Kamoshida, S. Murai, T. Narita, M. Omori, J. Suda, and T. Kachi, Phys. Status Solidi B 256, 1900367 (2019).

28) P. Hacke, T. Detchprohm, K. Hiramatsu, N. Sawaki, K. Tadatomo and K. Miyake, J. Appl. Phys. 76, 304 (1994).

29) Z.-Q. Fang, D. C. Look, J. Jasinski, M. Benamara, Z. Liliental-Weber, R. J. Molnar, Appl. Phys. Lett. 78, 332 (2001).

30) Z.-Q. Fang, D. C. Look, X.-L. Wang, J. Han, F. A. Khan, I. Adesida, Appl. Phys. Lett. 82, $1562(2003)$.

31) D. C. Look, G. C. Farlow, P. J. Drevinsky, D. F. Bliss, and J. R. Sizelove, Appl. Phys. Lett. 83, 3525 (2003).

32) Y. Tokuda, Y. Matsuoka, H. Ueda, O. Ishigro, N. Soejima and T. Kachi, Superlattice and Microstructures 40, 268 (2006).

33) A. R. Areheart, A. Corrion, C. Poblenz, J. S. Speck, U. K. Mishra, and S. A. Ringel, Appl. Phys. Lett. 93, 112101 (2008).

34) U. Honda, Y. Yamada, Y. Tokuda and K. Shiojima, Jpn. J. Appl. Phys. 51, 04DF04 (2012).

35) P. Kamyczek, E. Placzek-Popko, E. Zielony and Z. Zytkiewicz, Material Science-Poland 31, 572 (2013).

36) A. Y. Polyakov, N. B. Smirnov, E. B. Yakimov, I.-H. Lee, and S. J. Pearton, J. Appl. Phys. 119, 015103 (2016).

37) A. Uedono, S. Takashima, M. Edo, K. Ueno, H. Matsuyama, H. Kudo, H. Naramoto and S. Ishibashi, Phys. Status Solidi B 252, 2794 (2015).

38) A. Uedono, S. Takashima, M. Edo, K. Ueno, H. Matsuyama, W. Egger, T. Koschine, C. Hugenschmidt, M. Dickmann, K. Kojima, S.F. Chichibu and S. Ishibashi, Phys. Status Solidi B 255, 1700521 (2018).

39) A. Uedono, H. Iguchi, T. Narita, K. Kataoka, W. Egger, T. Koschine, C. Hugenschmidt, M. Dickmann, K. Shima, K. Kojima, S. F. Chichibu, and S. Ishibashi, Phys. Status Solidi B 256, 1900104 (2019). 
40) H. Iguchi, T. Narita, K. Kataoka, M. Kanechika, and A. Uedono, J. Appl. Phys. 126, 125102 (2019).

41) A. van Veen, H. Schut, M. Clement, J. M. M. de Nijs, A. Kruseman, M. R. Ijpma, Appl. Surf. Sci. 85, 216 (1995).

42) P. E. Blöchl, Phys. Rev. B 50, 17953 (1994).

43) S. Ishibashi, T. Tamura, S. Tanaka, M. Kohyama, K. Terakura, Phys. Rev. B 76, 153310 (2007).

44) S. F. Cagnina and E. H. Snow, J. Electrochem. Soc. 114, 1165 (1967).

45) M. Miczek, B. Adamowicz, C. Mizue, and T. Hashizume, Jpn. J. Appl. Phys. 48, 04C092 (2009).

46) S. M. Sze and K. K. Ng, Physics of Semiconductor Devices (Wiley, Hoboken, NJ, 2007) 3rd ed., Chap. 4.

47) H. Hasegawa and H. Ohno, J. Vac. Sci. \& Technol. B 4, 1130 (1986).

48) H. Hasegawa and M. Akazawa, Appl. Surf. Sci 254, 8005 (2008).

49) T. Sawada, K. Numata, S. Tohdoh, T. Saitoh and H. Hasegawa, Jpn. J. Appl. Phys. 32, 511 (1993).

50) T. Hashizume and R. Nakasaki, Appl. Phys. Lett. 80, 4564 (2002).

51) S. Limpijumnong and C. G. Van de Walle, Phys. Rev. B 69, 035207 (2004).

52) R. R. Wixom and A. F. Wright, Appl. Phys. Lett. 87, 201901 (2005).

53) G. A. Umana-Membreno, J. M. Dell, G. Parish, B. D. Nener, L. Faraone, S. Keller, and U. K. Mishra, J. Appl. Phys. 101, 054511 (2007).

54) F. Tuomisto, V. Ranki, D. C. Look, and G. C. Farlow, Phys. Rev. B 76, 165207 (2007).

55) K. H. Chow, G. D. Watkins, A. Usui, and M. Mizuta, Phys. Rev. Lett. 85, 2761 (2000).

56) G. Miceli and A. Pasquarello, Phys. Status Solidi PRL 11, 1700081 (2017).

57) J. L. Lyons and C. G. Van de Walle, NPJ Computational Materials 12, 1 (2017). 


\section{Figure Captions}

Fig. 1. Schematic diagram of sample preparation sequence.

Fig. 2. Calculated and measured profiles for $[\mathrm{Mg}],\left[V_{\mathrm{Ga}}\right]$ and $\left[V_{\mathrm{N}}\right]$.

Fig. 3. $C-V$ characteristics of MOS diodes with the $\mathrm{Mg}$ ion dose of $1.5 \times 10^{11} \mathrm{~cm}^{-2}$ annealed at (a) $300{ }^{\circ} \mathrm{C}$ and (b) $500{ }^{\circ} \mathrm{C}$ [experimental data in (a) is taken from Fig. 5(a) in Phys. Status Solidi B 256, 1900367 (2019) with permission].

Fig. 4. $D$ T distribution evaluated from $C-V$ characteristics for MOS diodes with $\mathrm{Mg}$ ion dose of $1.5 \times 10^{11} \mathrm{~cm}^{-2}$ annealed at $300{ }^{\circ} \mathrm{C}$ (solid circles) and $500{ }^{\circ} \mathrm{C}$ (solid rectangles).

Fig. 5. $C-V$ characteristics of MOS diodes with $\mathrm{Mg}$ ion dose of $1.5 \times 10^{12} \mathrm{~cm}^{-2}$ annealed at (a) $300{ }^{\circ} \mathrm{C}$ and (b) $500{ }^{\circ} \mathrm{C}$.

Fig. 6. $C-f$ characteristics of MOS diodes with $\mathrm{Mg}$ ion dose of $1.5 \times 10^{12} \mathrm{~cm}^{-2}$ annealed at (a) $300{ }^{\circ} \mathrm{C}$ and (b) $500{ }^{\circ} \mathrm{C}$. A difference in color indicates a difference in bias voltage.

Fig. 7. $G_{\mathrm{p}} / \omega$ extracted from $C-f$ characteristics versus $\omega$ for samples with $\mathrm{Mg}$ ion dose of $1.5 \times 10^{12} \mathrm{~cm}^{-2}$ annealed at (a) $300{ }^{\circ} \mathrm{C}$ and (b) $500{ }^{\circ} \mathrm{C}$. A difference in color indicates a difference in bias voltage. Solid circles show experimental data, whereas solid lines are fitted lines according to single-time-constant model.

Fig. 8. $D_{\mathrm{T}}$ distribution evaluated from $C-f$ characteristics for the samples with $\mathrm{Mg}$ ion dose of $1.5 \times 10^{12} \mathrm{~cm}^{-2}$.

Fig. 9. $S$ as a function of incident positron energy for samples with $\mathrm{Mg}$ ion doses of (a) $1.5 \times 10^{11} \mathrm{~cm}^{-2}$ and (b) $1.5 \times 10^{12} \mathrm{~cm}^{-2}$. Fine solid lines are fitting lines to the experimental data.

Fig. 10. $S$ depth profiles obtained from the analysis of the $S-E$ curves for the samples with doses of (a) $1.5 \times 10^{11} \mathrm{~cm}^{-2}$ and (b) $1.5 \times 10^{12} \mathrm{~cm}^{-2}$. (The broken lines, the one-dot-chain lines, and the solid lines are for $S$ for as-implanted, $300{ }^{\circ} \mathrm{C}$-annealed, and $500{ }^{\circ} \mathrm{C}$-annealed samples, respectively.) The depth profiles of the as-implanted $\mathrm{Mg}$ concentration measured by SIMS are also plotted by the solid circles. 
Fig. 11. $S-W$ relationship for samples with $\mathrm{Mg}$ ion doses of (a) $1.5 \times 10^{11} \mathrm{~cm}^{-2}$ and (b) $1.5 \times 10^{12} \mathrm{~cm}^{-2} .(S, W)$ values were measured at an incident positron energy of $5.1 \mathrm{keV}$. The brown DF data point indicates the result for the unimplanted $\mathrm{GaN}$. The $(S, W)$ values (blue) calculated using QMAS for positron annihilation in DF, $V_{\mathrm{Ga}}, V_{\mathrm{Ga}}\left(V_{\mathrm{N}}\right)_{n}(n=1-4),\left(V_{\mathrm{Ga}} V_{\mathrm{N}}\right) 2$, $\left(V_{\mathrm{Ga}} V_{\mathrm{N}}\right)_{3}$, and $\left(V_{\mathrm{Ga}}\right)_{2}\left(V_{\mathrm{N}}\right)_{7}$, are also plotted.

Fig. 12. $D_{\mathrm{T}}$ dependences of (a) $\mathrm{d} \psi_{\mathrm{S}} / \mathrm{d} V$ and (b) $C_{\mathrm{LF}}$ calculated according to Eqs. (8) and (9), respectively. 


\begin{tabular}{c}
$\mathrm{n}-\mathrm{GaN}: 3 \mu \mathrm{m}$ \\
$n=5 \times 10^{17} \mathrm{~cm}^{-3}$ \\
\hline $\mathrm{n}^{+}-\mathrm{GaN}$ substrate \\
\hline
\end{tabular}

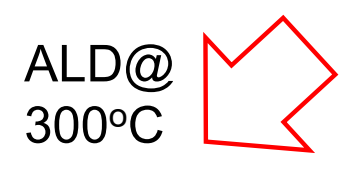

\begin{tabular}{|c|}
\hline $\mathrm{ALD} \mathrm{Al}$ \\
\hline $\mathrm{Og} \mathrm{O}_{3}(20 \mathrm{~nm})$ \\
\hline $\mathrm{n}-\mathrm{GaN}$ \\
\hline $\mathrm{n}^{+}-\mathrm{GaN}$ substrated $\mathrm{GaN}$ \\
\hline
\end{tabular}

Annealing $500{ }^{\circ} \mathrm{C} / 3 \mathrm{~min}$
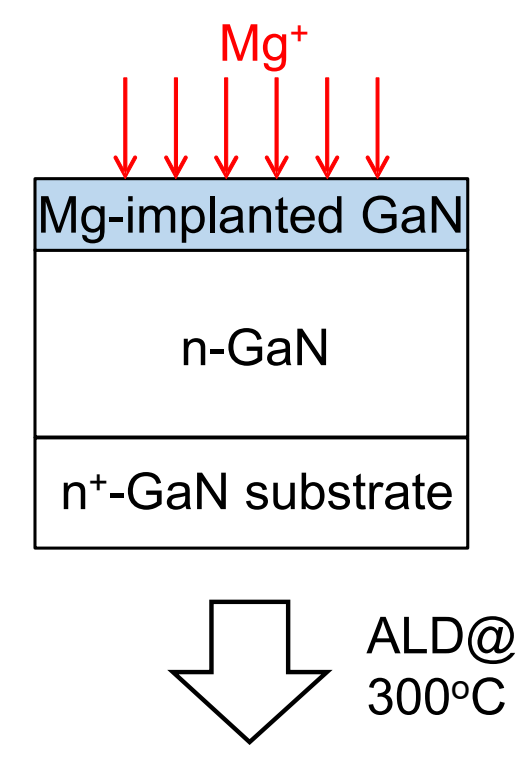

$\mathrm{Ni} / \mathrm{Au}$

\begin{tabular}{|c|}
\hline ALD $\mathrm{Al}_{2} \mathrm{O}_{3}(30 \mathrm{~nm})$ \\
\hline Mg-implanted $\mathrm{GaN}$ \\
\hline $\mathrm{n}-\mathrm{GaN}$ \\
\hline $\mathrm{n}^{+}$-GaN substrate \\
\hline Ohmic Contact \\
\hline
\end{tabular}

PMA

$300^{\circ} \mathrm{C} / 3 \mathrm{~h}$

Fig.1. 


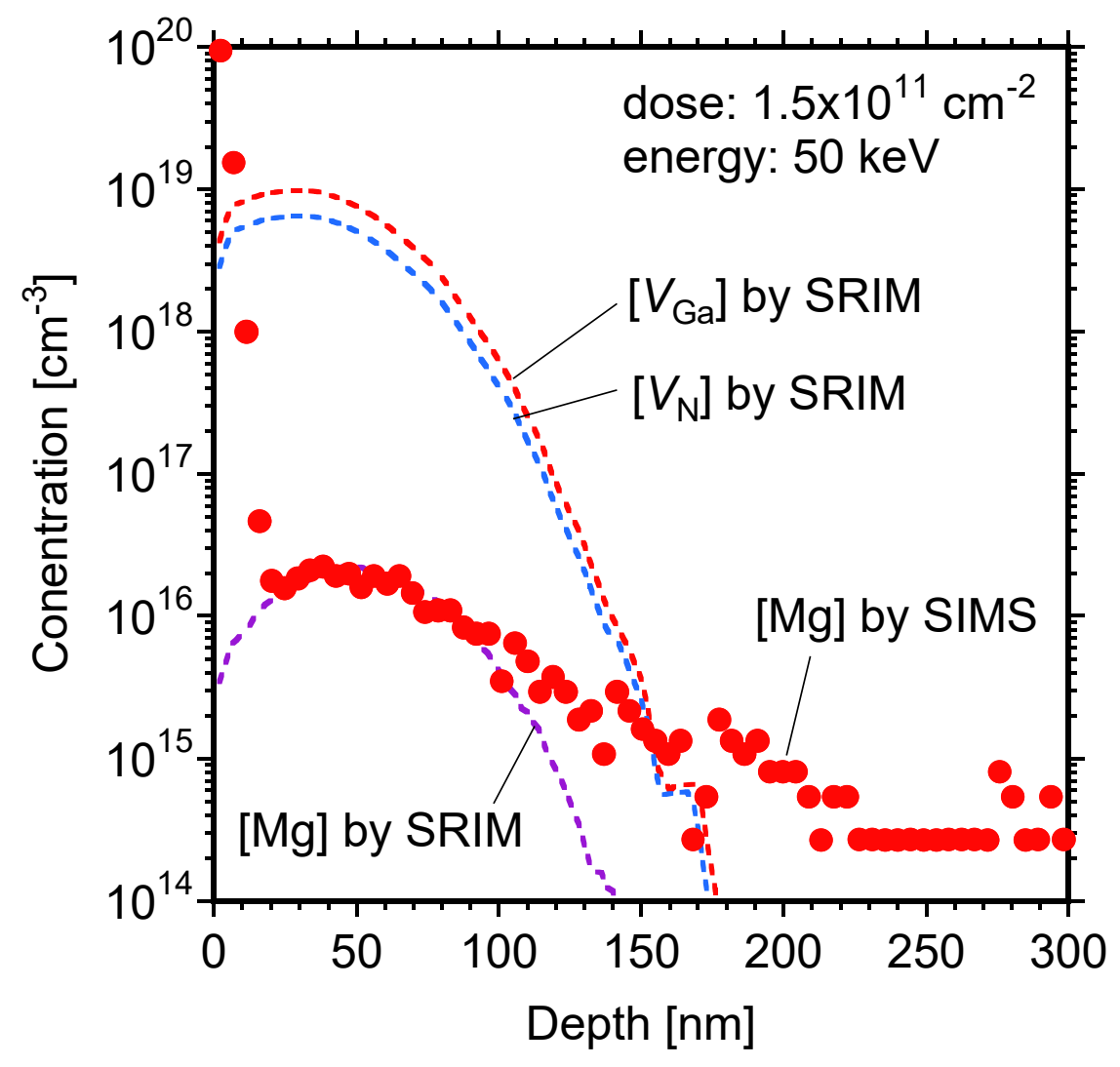

Fig. 2 

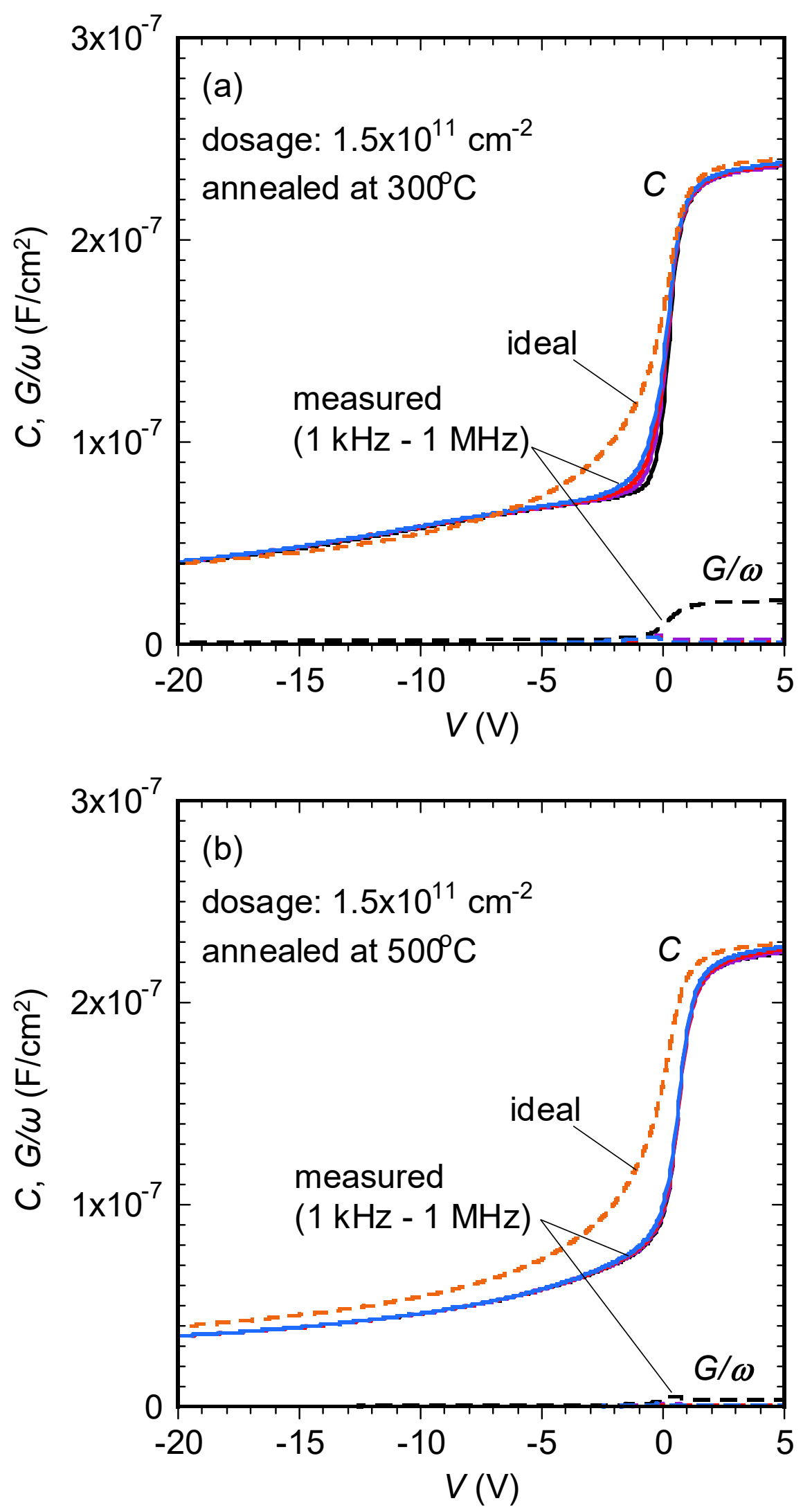

Fig. 3 


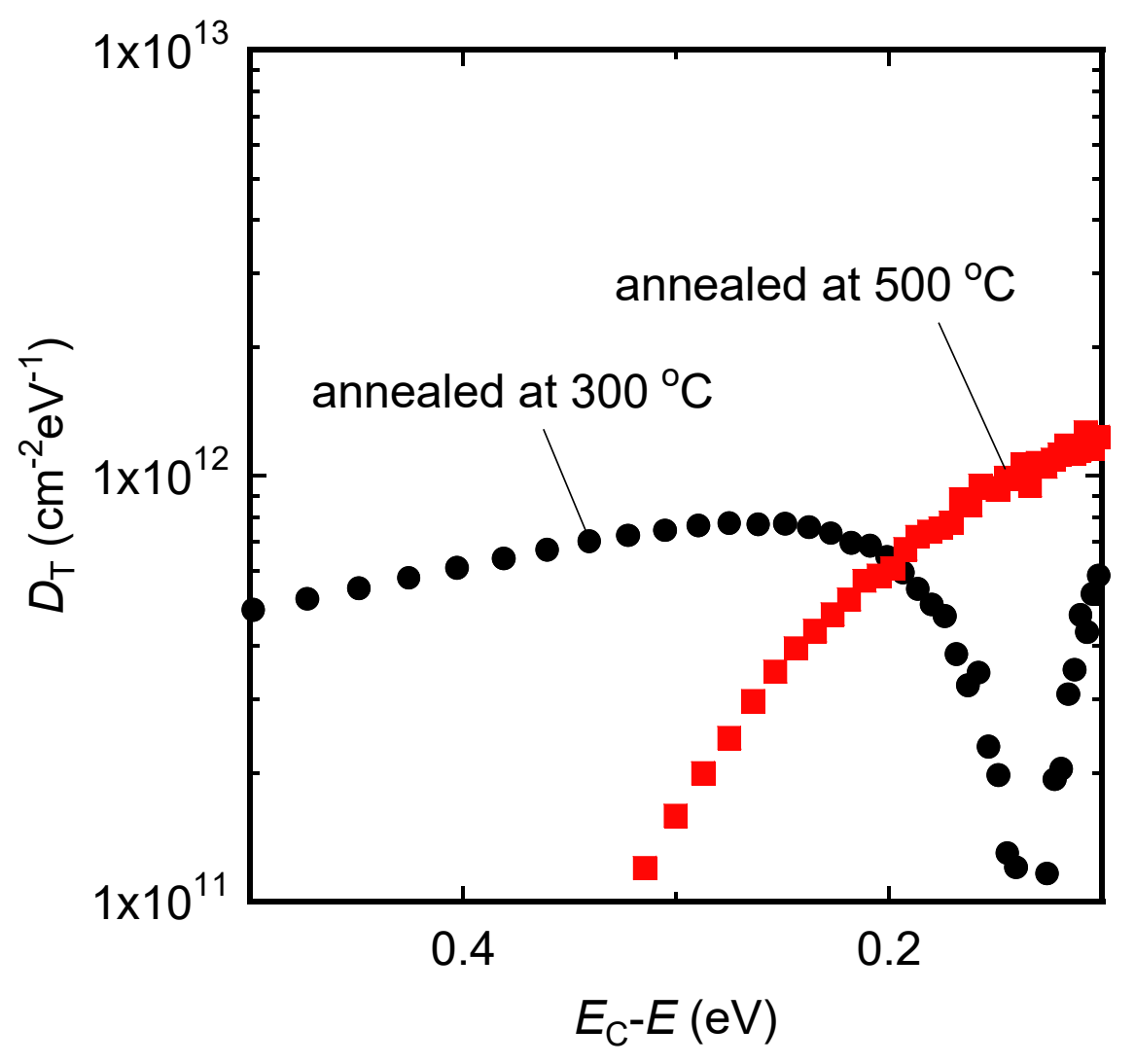

Fig. 4 

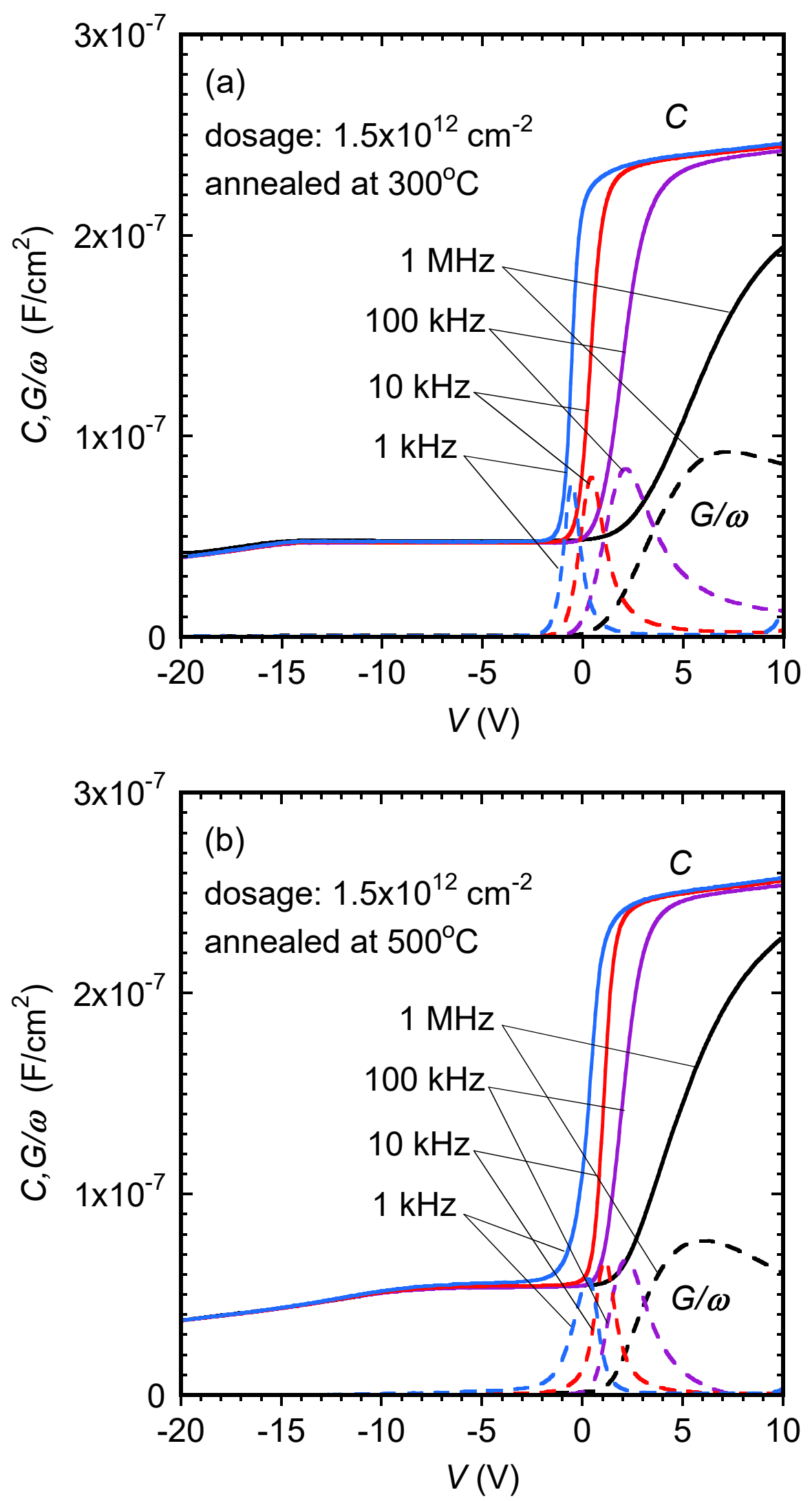

Fig. 5 

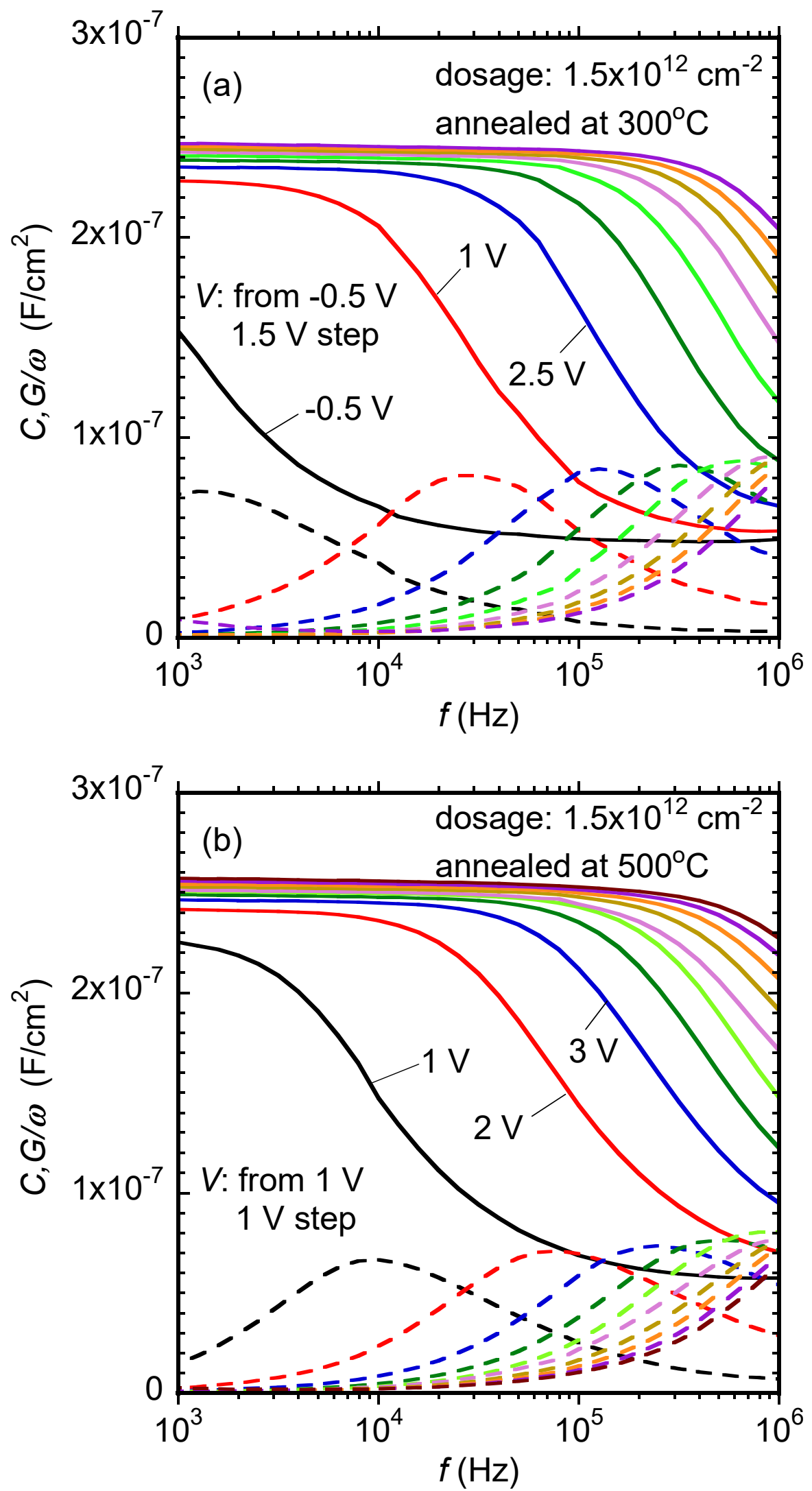

Fig. 6 

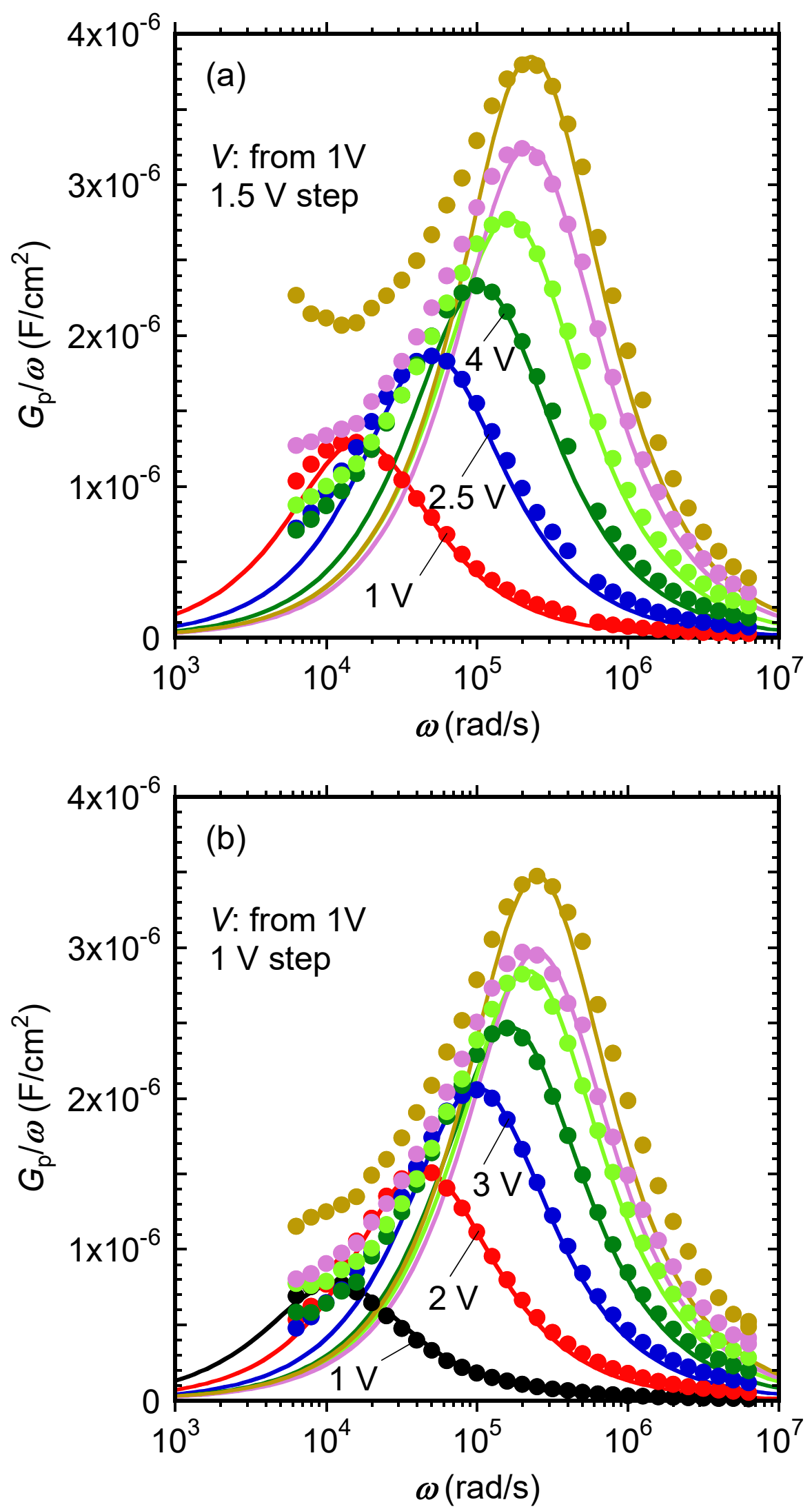

Fig. 7 


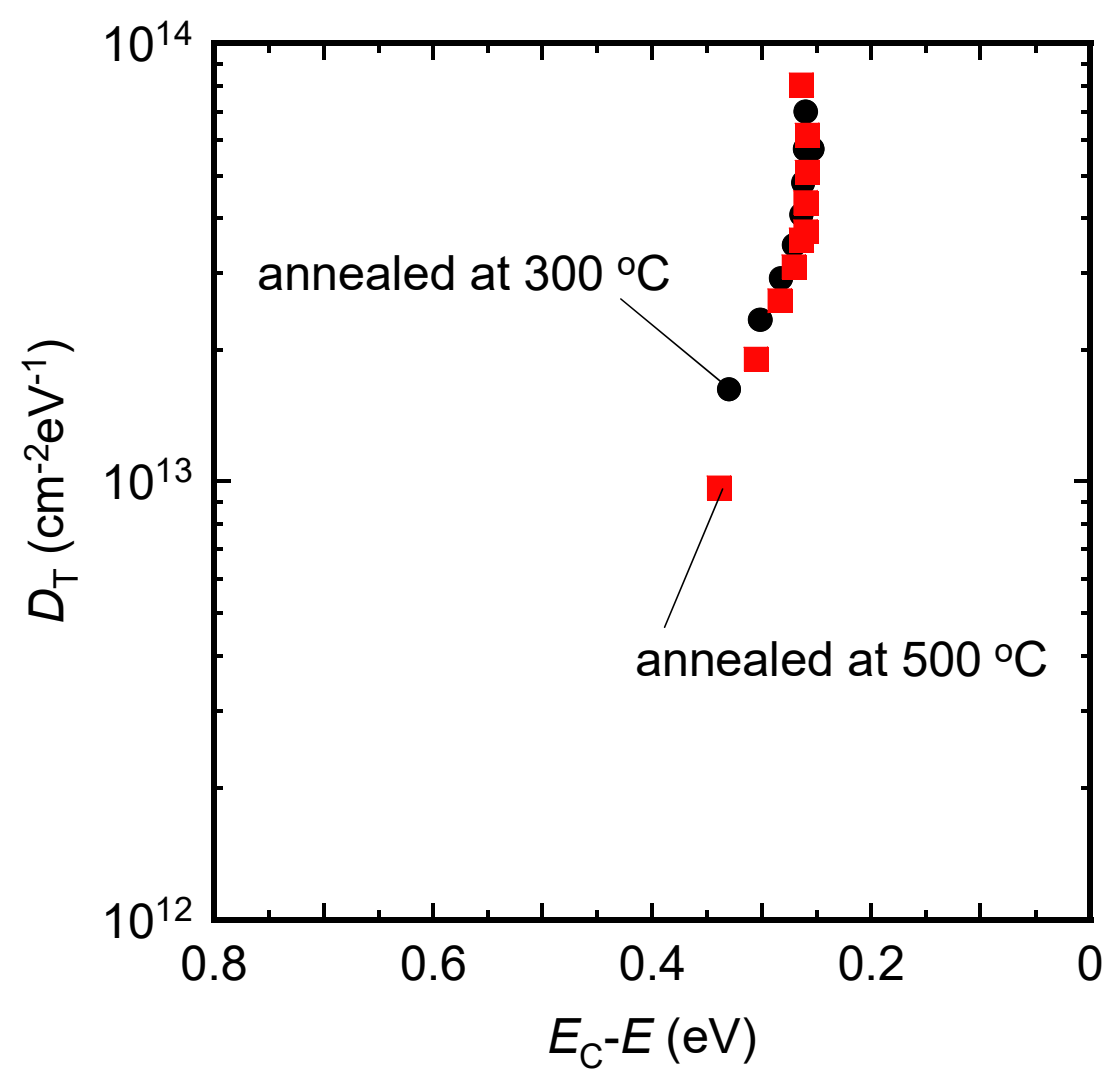

Fig. 8 
Mean implantation depth of positrons $(\mathrm{nm})$

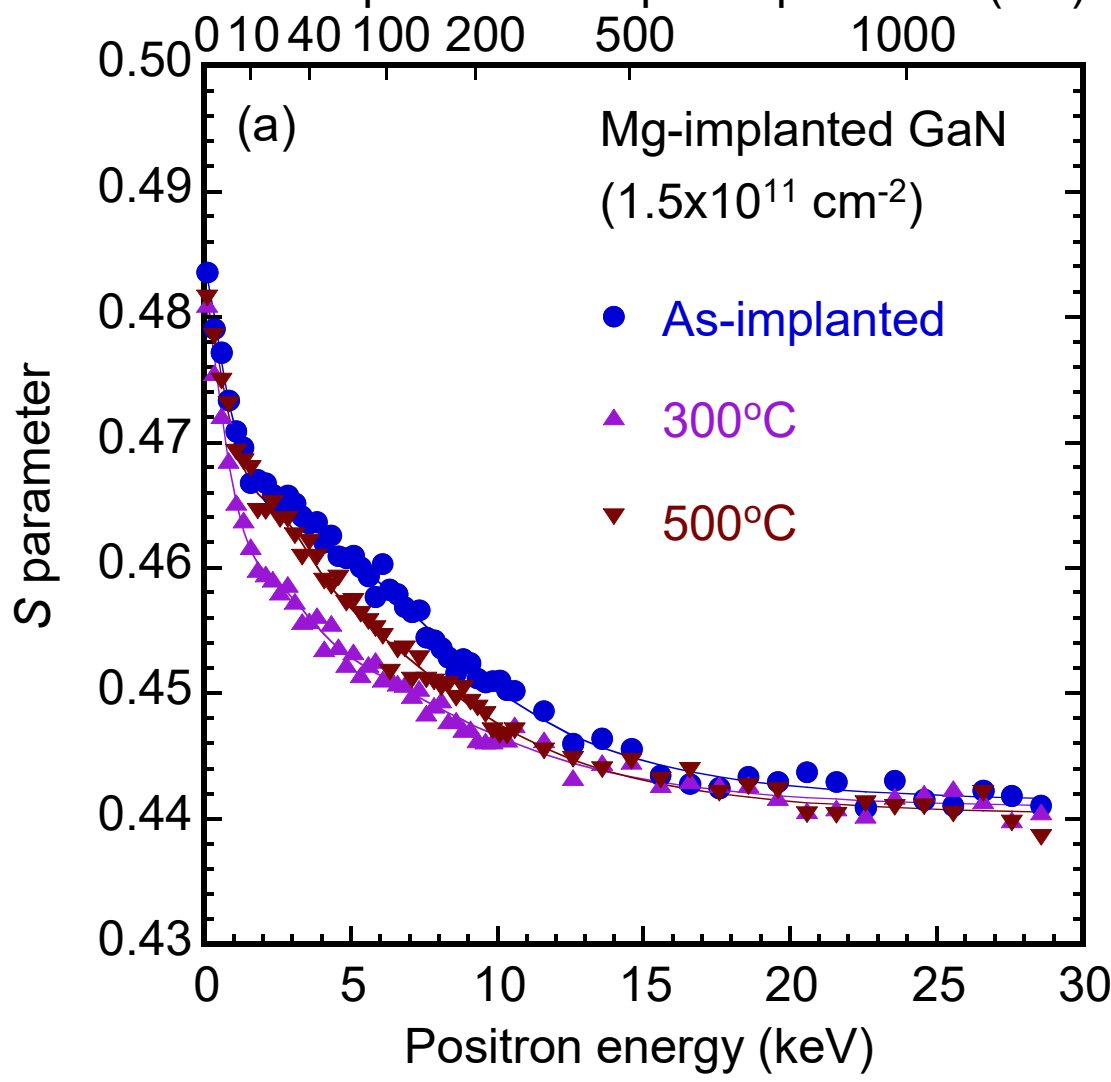

Mean implantation depth of positrons $(\mathrm{nm})$

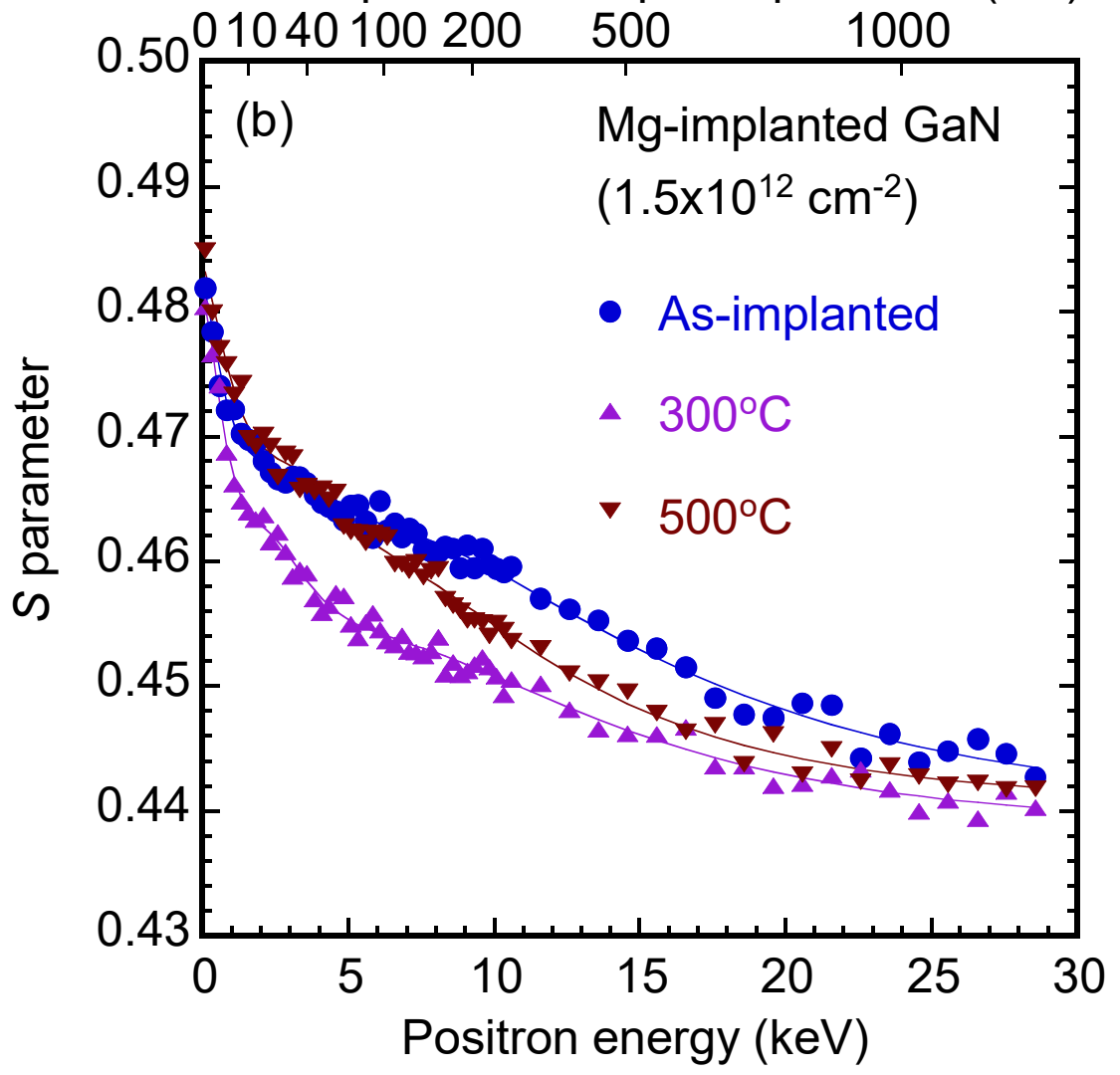

Fig. 9 

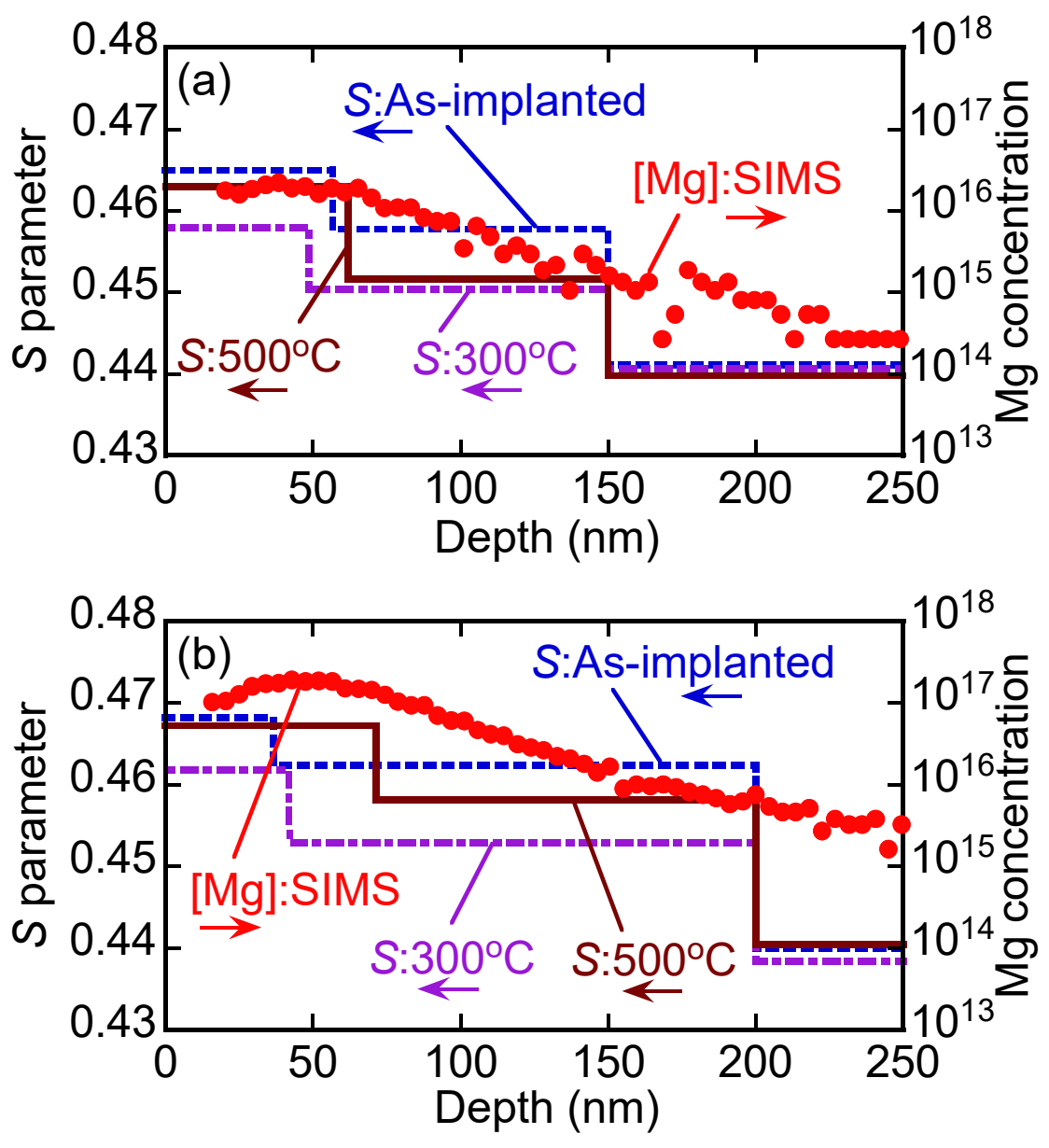

Fig. 10 

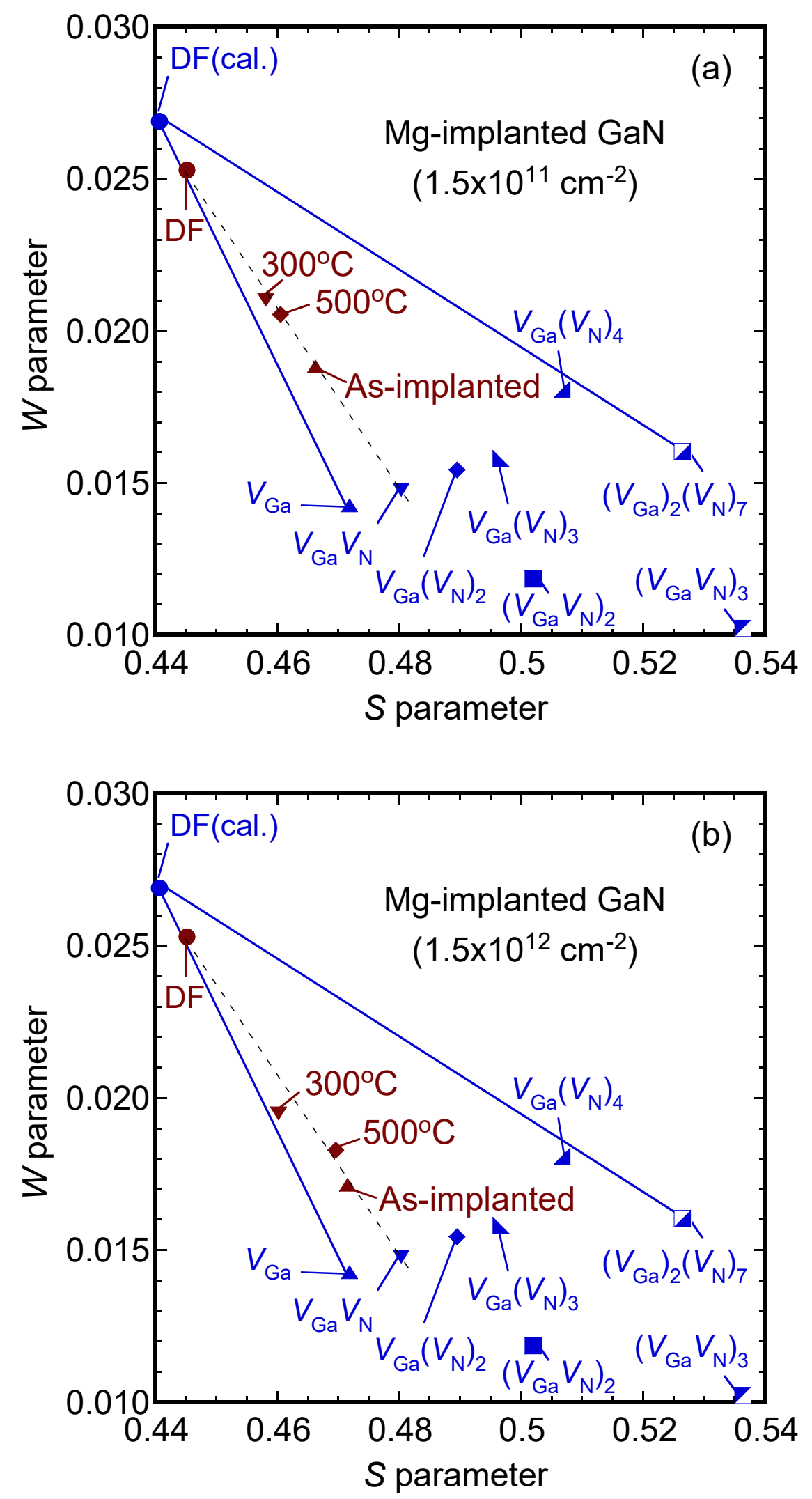

Fig. 11 

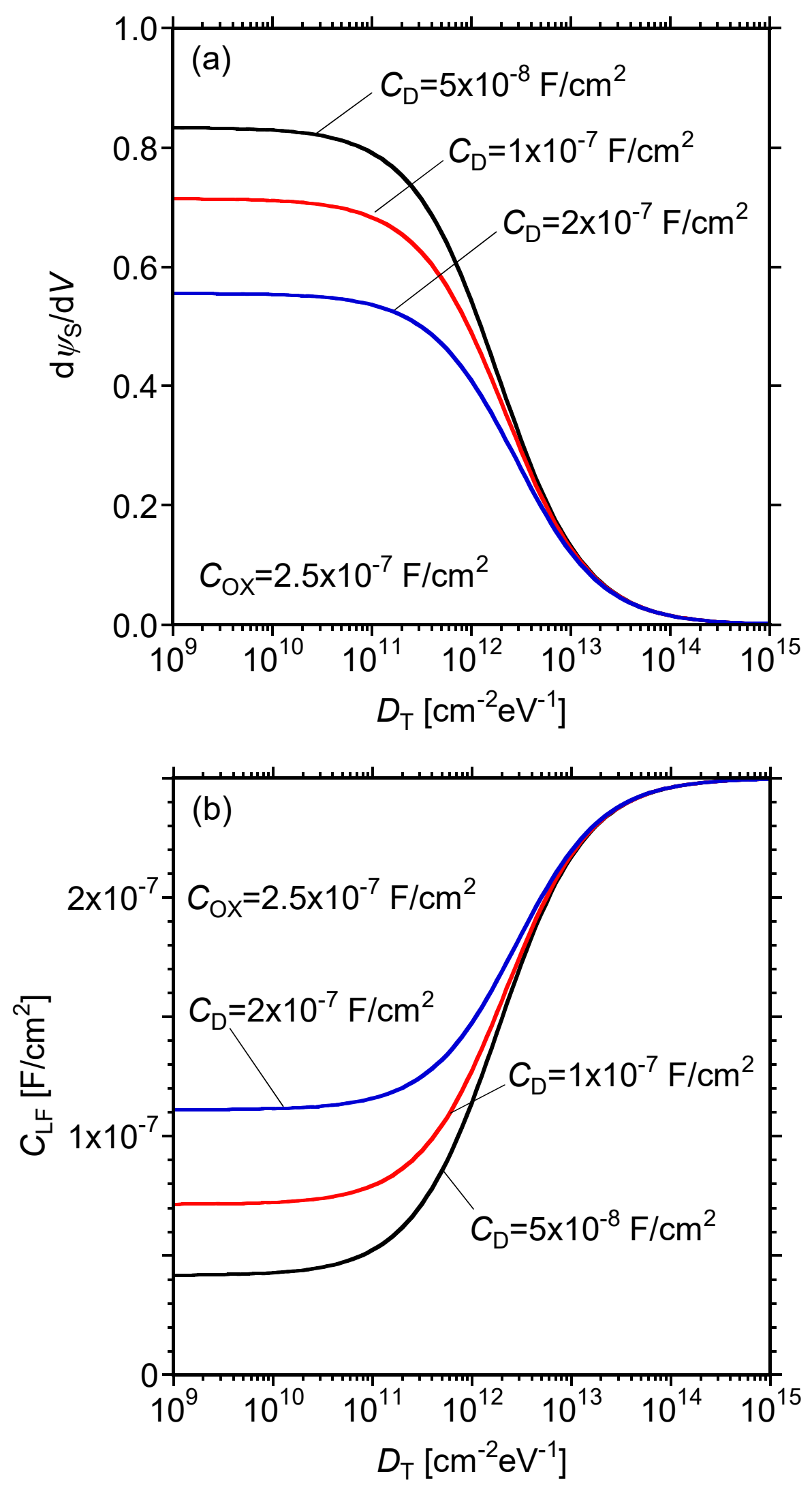

Fig. 12 